(2) OPEN ACCESS
- Additional supplemental material is published online only. To view, please visit the journal online (http://dx.doi. org/10.1136/heartjnl-2021319561).

For numbered affiliations see end of article.

Correspondence to Dr Pankaj Garg, Cardiology, Norfolk and Norwich University Hospital NHS Trust, Norwich NR4 7UQ, Norfolk, UK; P.Garg@uea.ac.uk

Received 20 April 2021 Accepted 12 July 2021 Published Online First 6 August 2021

\section{Linked}

- http://dx.doi.org/10.1136/ heartjnl-2021-319945

Check for updates

(C) Author(s) (or their employer(s)) 2021. Re-use permitted under CC BY. Published by BMJ.

To cite: Jenkins $S$, Alabed $S$, Swift A, et al. Heart

2021;107:1826-1834.

\title{
Diagnostic accuracy of handheld cardiac ultrasound device for assessment of left ventricular structure and function: systematic review and meta-analysis
}

\author{
Sam Jenkins (D) ,' Samer Alabed (D) , ${ }^{1}$ Andrew Swift, ${ }^{2}$ Gabriel Marques, ${ }^{3}$ \\ Alisdair Ryding, ${ }^{3}$ Chris Sawh, ${ }^{3}$ James Wardley, ${ }^{3}$ Benoy Nalin Shah (1) , \\ Peter Swoboda, ${ }^{5}$ Roxy Senior (D) , ${ }^{6}$ Robin Nijveldt, ${ }^{7}$ Vassilios S Vassiliou (D) , \\ Pankaj Garg ${ }^{3}$
}

\section{ABSTRACT}

Objective Handheld ultrasound devices (HUD) has diagnostic value in the assessment of patients with suspected left ventricular (LV) dysfunction. This meta-analysis evaluates the diagnostic ability of HUD compared with transthoracic echocardiography (TTE) and assesses the importance of operator experience. Methods MEDLINE and EMBASE databases were searched in October 2020. Diagnostic studies using HUD and TTE imaging to determine LV dysfunction were included. Pooled sensitivities and specificities, and summary receiver operating characteristic curves were used to determine the diagnostic ability of HUD and evaluate the impact of operator experience on test accuracy.

Results Thirty-three studies with 6062 participants were included in the meta-analysis. Experienced operators could predict reduced LV ejection fraction (LVEF), wall motion abnormality (WMA), LV dilatation and LV hypertrophy with pooled sensitivities of $88 \%, 85 \%, 89 \%$ and $85 \%$, respectively, and pooled specificities of $96 \%, 95 \%, 98 \%$ and $91 \%$, respectively. Non-experienced operators are able to detect cardiac abnormalities with reasonable sensitivity and specificity. There was a significant difference in the diagnostic accuracy between experienced and inexperienced users in LV dilatation, LVEF (moderate/severe) and WMA. The diagnostic OR for LVEF (moderate/severe), LV dilatation and WMA in an experienced hand was $276(95 \% \mathrm{CI} 58$ to 1320$), 225(95 \% \mathrm{Cl} 87$ to 578$)$ and $90(95 \% \mathrm{Cl} 31$ to 265), respectively, compared with $41(95 \% \mathrm{Cl} 18$ to 94), 45 (95\% Cl 16 to 123) and 28 (95\% Cl 20 to 41$)$ respectively, for inexperienced users.

Conclusion This meta-analysis is the first to establish HUD as a powerful modality for predicting LV size and function. Experienced operators are able to accurately diagnose cardiac disease using HUD. A cautious, supervised approach should be implemented when imaging is performed by inexperienced users. This study provides a strong rationale for considering HUD as an auxiliary tool to physical examination in secondary care, to aid clinical decision making when considering referral for TTE.

Trial registration number CRD42020182429.

\section{INTRODUCTION}

Echocardiography is the first-line imaging modality for assessing cardiac size and function. Indications for transthoracic echocardiography (TTE) as recommended by the British Society of Echocardiography and other international societies include but not limited to: murmur in the presence of cardiac or respiratory symptoms, valvular stenosis or regurgitation, ischaemic heart disease, any suspicion of heart failure (HF) and arrhythmias. ${ }^{1-3}$ TTE allows determination of left ventricular (LV) dysfunction by assessing LV cavity size, wall thickness, valvular appearances and function as well as for the presence of abnormal blood flow within the heart. ${ }^{4}$

The miniaturisation of ultrasound technology has led to the introduction of handheld cardiac ultrasound devices (HUD). ${ }^{5}$ The portability and accessibility of HUD allow for the augmentation of the bedside physical examination. While physical examination remains the primary method for screening cardiovascular disease, the quality and subsequent referral to echocardiography depend on the examiner's experience and skill, or lack thereof. ${ }^{6}$ HUD therefore can bridge the gap between the physical examination and the more costly and timeconsuming departmental TTE.

Several recent studies have assessed the performance of HUD in diagnosing cardiac disease. The aim of this systematic review and meta-analysis is to assess the diagnostic accuracy of HUD to detect LV abnormalities when compared with TTE in both experienced and non-experienced users.

\section{METHODS}

The Preferred Reporting Items for Systematic Reviews and Meta-Analyses guidelines and the Cochrane Handbook of Diagnostic Test Accuracy were followed in the study selection, review process and evidence synthesis. ${ }^{78}$

\section{Patient and public involvement}

Patients or the public were not involved in the design, or conduct, or reporting, or dissemination plans of our research.

\section{Eligibility criteria}

Any study comparing the diagnostic performance of HUD and TTE was eligible. The index test was any type or size of a HUD performed by operators of any level of experience. The reference standard was 
TTE performed by experienced imagers. Studies were included if subjects were aged $>18$ years, sensitivity, specificity, true positive and negative and false positive and negative findings were reported or if diagnostic data could be extrapolated from the results. Studies with a sample size of $<20$ participants were excluded.

\section{Search strategy and study selection}

MEDLINE (ProQuest, 1946 to 13 October 2020), EMBASE (Ovid, 1974-2020 week 42) were searched on 13 October 2020. No search filters were applied. The full search strategy is available in the online supplemental document. The references of the included studies were also screened for relevant studies.

Two authors (SJ and PG) screened the titles and abstracts and reviewed full texts for inclusion criteria. Any disagreements were discussed with a third author (SA). Data extraction and risk of bias analysis was performed by two authors (SJ and PG) and disagreements discussed with a third author (SA). Methods for the quality assessment of individual studies are detailed in online supplemental figure 1.

\section{Statistical analysis}

A bivariate random-effects model was used to obtain the summary point for the sensitivity and specificity and estimate the corresponding 95\% CI and prediction regions for all metaanalyses including four or more studies. The metandi command in Stata V.16 (StataCorp, College Station, Texas, USA) was used to perform the analyses and create summary receiver operating characteristics (SROC). The mada package in $\mathrm{R}$ was used to calculate the diagnostic ORs (DORs) for each study and the summary DOR for the pooled results with their respective 95\% CIs (R Core Team, R: A Language and Environment for Statistical Computing, Vienna, Austria: R Foundation for Statistical Computing, 2020). The Wilson method was used to calculate the CIs for sensitivities, specificities and false positive rates. The Yates correction was used for testing the equality of sensitivities and specificities. The input for the mada command was the number of true positives (TP), false negatives (FN), true negatives (TN) and false postives (FP) for each study.

The effect of operator experience on the effect size of the diagnostic accuracy was assessed in a subgroup analysis and graphically represented in SROC curves comparing the diagnostic accuracy of experienced and inexperienced operators. A meta-regression was also performed to assess the effect of operator experience.

\section{RESULTS}

\section{Search results}

Our comprehensive search identified 33 studies which were incorporated into the meta-analysis. The results of the literature search are outlined in the study flow diagram (figure 1).

\section{Description of included studies}

All studies had a prospective design, with consecutive or random patient selection reported in 21 studies. The studies were published between 2002 and 2019. The majority of studies (22 studies) had a large sample size $\geq 100$ participants, with the largest study by Galasko et $a l^{8}$ recruiting 562 patients. ${ }^{9}$ Individual study data incorporated into the meta-analysis can be found in online supplemental table 1 and a summary graph of the overall risk of bias is shown in online supplemental figure 1.

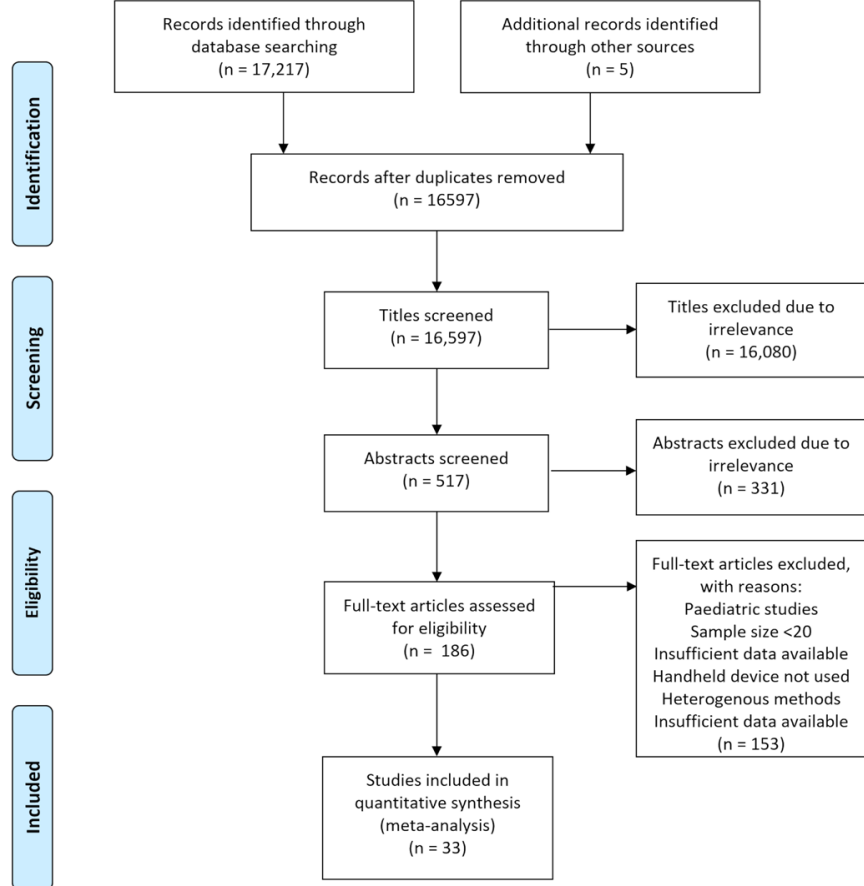

Figure 1 The Preferred Reporting Items for Systematic Reviews and Meta-Analyses flow chart of literature search.

\section{Study characteristics}

A total of 6062 patients conducted in 13 different countries were included in the meta-analysis. The mean age of patients was $65 \pm 5$ years with a slight male predominance (54\%). Study characteristics are presented in table 1. Study-level HUD data including sensitivity and specificity to predict reduced LV ejection fraction (LVEF), wall motion abnormality (WMA), LV dilatation and hypertrophy $(\mathrm{LVH})$ are reported in the online supplemental materials.

\section{Assessment of methodological quality}

The majority of studies (19/25) reported a prospective and consecutive or random design. Only one study reported that HUD assessors were unblinded to TTE results while three studies were judged to incorporate a high risk of bias with TTE assessors unblinded to HUD results. There was some concern for bias when time between HUD and TTE was > 48 hours. One study was judged to have a high risk of bias as time between HUD and TTE was $>7$ days. ${ }^{10}$ The detailed results of the quality assessment are outlined in online supplemental figure 2 .

\section{Meta-analysis of HUD indices}

Each characteristic was separated into subgroups based on the investigator's level of experience. Inexperienced operators were those that learnt HUD as part of the study with limited or no prior echocardiography experience. This subgroup included nurses, medical students, residents, general practitioners and inexperienced cardiology trainees. Experienced operators were those who had undergone level II/III echocardiography training or who were stated to be experienced, expert, or trained in echocardiography.

Experienced operators could determine reduced LVEF, LV dilatation, WMA and LVH with pooled sensitivities of $88 \%$, $89 \%, 85 \%$ and $85 \%$, respectively (figures $2-4$ ). In inexperienced hands, pooled sensitivities measured were $83 \%, 68 \%, 78 \%$ and $80 \%$, respectively. Pooled specificities of HUD by experienced 
Table 1 Characteristics of included studies

\begin{tabular}{|c|c|c|c|c|c|c|c|c|}
\hline Study & Country & Design & Study period & Size & Male (\%) & Age, years & Level of experience & HUD \\
\hline Aldaas et $\left.a\right|^{21}$ & USA & Consecutive & NR & 70 & 50 & $61 \pm 18$ & Both & Vscan \\
\hline Alexander et $a l^{22}$ & USA & NR & $\begin{array}{l}\text { April-November } \\
2000\end{array}$ & 537 & 53 & 59 & Inexperienced & Optigo \\
\hline Andersen et $a l^{23}$ & Norway & Random & $\begin{array}{l}\text { March-September } \\
2010\end{array}$ & 108 & 64 & $69.1 \pm 14$ & Experienced & Vscan \\
\hline Biais et $a l^{24}$ & France & Consecutive & $\begin{array}{l}\text { February-May } \\
2011\end{array}$ & 151 & 35 & $55 \pm 20$ & Experienced & Vscan \\
\hline Bruce et $a l^{9}$ & USA & NR & NR & 374 & 62 & 66 & Both & SonoHeart \\
\hline Coletta et $a l^{25}$ & Italy & Consecutive & April-June 2003 & 112 & 57 & $61 \pm 11$ & Experienced & Optigo \\
\hline Cullen et $a l^{26}$ & USA & Consecutive & 2012-2013 & 190 & 49 & $62 \pm 17$ & Experienced & Vscan \\
\hline DeCara et $a l^{27}$ & USA & NR & NR & 300 & NR & NR & Experienced & Optigo \\
\hline Fedson et $a l^{28}$ & USA & Consecutive & NR & 103 & NR & NR & Inexperienced & Optigo \\
\hline Galasko $^{8}$ & UK & Consecutive & 2000-2001 & 562 & 56 & $62 \pm 11$ & Experienced & Optigo \\
\hline Ghani et $a l^{29}$ & USA & Consecutive & NR & 80 & 51 & $75 \pm 13$ & Inexperienced & Optigo \\
\hline Giusca et $a{ }^{\beta 0}$ & Romania & Consecutive & NR & 56 & 54 & $60 \pm 12$ & Inexperienced & Acuson P10 \\
\hline Gulič et $a l^{31}$ & Slovenia & Consecutive & NR & 200 & 43 & 70 & Both & Vscan \\
\hline $\mathrm{Khan}^{32}$ & USA & Consecutive & 2012-2013 & 240 & 53 & $71 \pm 17$ & Experienced & Vscan \\
\hline Kirkpatrick ${ }^{33}$ & USA & NR & NR & 63 & 46 & $65 \pm 16$ & Inexperienced & Optigo \\
\hline Kobal et $a l^{34}$ & USA & Consecutive & NR & 61 & 62 & $70 \pm 19$ & Inexperienced & Optigo \\
\hline Liebo $^{35}$ & USA & Consecutive & $\begin{array}{l}\text { February-March } \\
2010\end{array}$ & 97 & 45 & $68 \pm 17$ & Both & Vscan \\
\hline López-Palmero et a/36 & Spain & NR & $\begin{array}{l}\text { July-December } \\
2013\end{array}$ & 223 & 42 & 76 & Inexperienced & Vscan \\
\hline Lucas et $a l^{37}$ & USA & Consecutive & March-May 2007 & 322 & 53 & $56 \pm 13$ & Inexperienced & Micromaxx \\
\hline Lucas et $a l^{38}$ & USA & Consecutive & 2008-2009 & 210 & 55 & 55 & Inexperienced & NR \\
\hline Martin et $a l^{39}$ & USA & Consecutive & 2004-2005 & 354 & 47 & $63 \pm 19$ & Inexperienced & Sonosite Elite \\
\hline Mehta et $a l^{40}$ & USA & NR & NR & 250 & 66 & $61 \pm 15$ & Experienced & Vscan \\
\hline Mjølstad et al/1 & Norway & Consecutive & April-June 2011 & 199 & 54 & $66 \pm 18$ & Inexperienced & Vscan \\
\hline Nilsson et $a l^{42}$ & Sweden & NR & 2016-2017 & 100 & 55 & $70 \pm 12$ & Inexperienced & Vscan \\
\hline Olesen $^{43}$ & Denmark & NR & NR & 260 & 49 & 80 & Experienced & Vscan \\
\hline Perez-Avraham et al ${ }^{44}$ & Israel & Consecutive & $\begin{array}{l}\text { July-December } \\
2004\end{array}$ & 85 & 37 & $59 \pm 14$ & Inexperienced & Optigo \\
\hline Razi et $a l^{45}$ & USA & Consecutive & NR & 50 & 58 & $57 \pm 17$ & Inexperienced & Vscan \\
\hline Ruddox et $a l^{46}$ & Norway & NR & 2011-2012 & 303 & 61 & 73 & Inexperienced & Vscan \\
\hline Stokke et $a l^{13}$ & Norway & Random & $\begin{array}{l}\text { February-May } \\
2012\end{array}$ & 72 & 72 & $65 \pm 16$ & Both & Vscan \\
\hline Vignon et al/ ${ }^{47}$ & France & Consecutive & NR & 55 & 69 & $61 \pm 16$ & Experienced & SonoHeart \\
\hline Vourvouri et al ${ }^{48}$ & The Netherlands & Consecutive & NR & 88 & 64 & $59 \pm 12$ & Experienced & SonoHeart or Optigo \\
\hline Wejner-Mik et a/49 & Poland & Consecutive & NR & 87 & 67 & $61 \pm 16$ & Experienced & Lumify \\
\hline Xie et $a l^{50}$ & USA & Consecutive & NR & 100 & 55 & $59 \pm 17$ & Experienced & SonoHeart \\
\hline
\end{tabular}

HUD, handheld ultrasound devices; NR, not reported.

users compared with inexperienced users for reduced LVEF, LV dilatation, WMA and LVH measured $96 \%$ vs $89 \%$, $98 \%$ vs $95 \%$, $95 \%$ vs $88 \%$ and $91 \%$ vs $87 \%$. Online supplemental figure 3 displays a box plot assessing the pooled accuracy of HUD to diagnose moderate/severe LVEF (<45\%). SROC curves show an improvement in diagnostic accuracy of reduced LVEF, WMA and LV dilatation when performed by experienced users (figure 5). A summary of the meta-analysis data is provided in table 2 .

The highest diagnostic ORs were in assessing LV dilatation (DOR 96, 95\% CI 40 to 229). This result indicates that the odds of a positive result in a patient with LV dilatation is approximately 96 times higher than the odds for a positive result in a person with no LV dilatation. There was a significant difference in the diagnostic accuracy between experienced and inexperienced users in LV dilatation, LVEF (moderate/severe) and WMA. The DOR for LVEF (moderate/severe), LV dilatation and WMA in an experienced hand was 276, 225 and 90, respectively, compared with 41, 45 and 28, respectively, for inexperienced users. The total effect sizes and subgroup differences test comparing the HUD parameters in experienced and inexperienced users are shown in online supplemental table 2. A sensitivity analysis excluding studies that visually assessed LVH and LV dilatation showed that quantitative analysis improves the diagnostic accuracy of HUD. Meta-regression analysis confirmed experience to be a significant factor in the detection of any degree of LVEF dysfunction $(p=0.04)$ and WMA $(p=0.01)$ (online supplemental table 3).

\section{Heterogeneity}

Heterogeneity can be visualised in all the forest plots depicting sensitivity and in the LVEF and LVH plot depicting specificity. Despite there being some overlap of CIs, sampling variation 


\section{LVEF}

Experienced

Aldaas(exp) 2019

Biais 2012

Decara (exp) 2003

Fedson 2003

Galasko 2003

Gulic (exp) 2016

Khan 2014

Vignon 2004

Xie 2006

Random effects model

Inexperienced

Aldaas(inexp) 2019

Alexander 2004

Decara (inexp) 2003

Gulic (inexp) 2016

Kobal 2005

Lopez-Palmero 2015

Martin 2009

Nilsson 2019

Oleson 2015

Random effects model

Sensitivity

Specificity

$0.64[0.35 ; 0.87]$

$0.86[0.67 ; 0.96]$

$0.89[0.75 ; 0.97]$

$0.73[0.39 ; 0.94]$

$0.96 \quad[0.87 ; 1.00]$

$0.73[0.50 ; 0.89]$

$0.93[0.84 ; 0.98]$

$0.91[0.71 ; 0.99]$

$0.91[0.76 ; 0.98]$

$0.88[0.81 ; 0.92]$

$0.75[0.35 ; 0.97]$

$0.82[0.72 ; 0.89]$

$0.96 \quad[0.85 ; 0.99]$

$0.82[0.60 ; 0.95]$

$0.86[0.65 ; 0.97]$

$0.95[0.88 ; 0.99]$

$0.81[0.73 ; 0.87]$

$0.47[0.24 ; 0.71]$

$0.65[0.56 ; 0.73]$

$0.83[0.71 ; 0.90]$

Fixed effects (plural) mode $0.86[0.80 ; 0.90]$
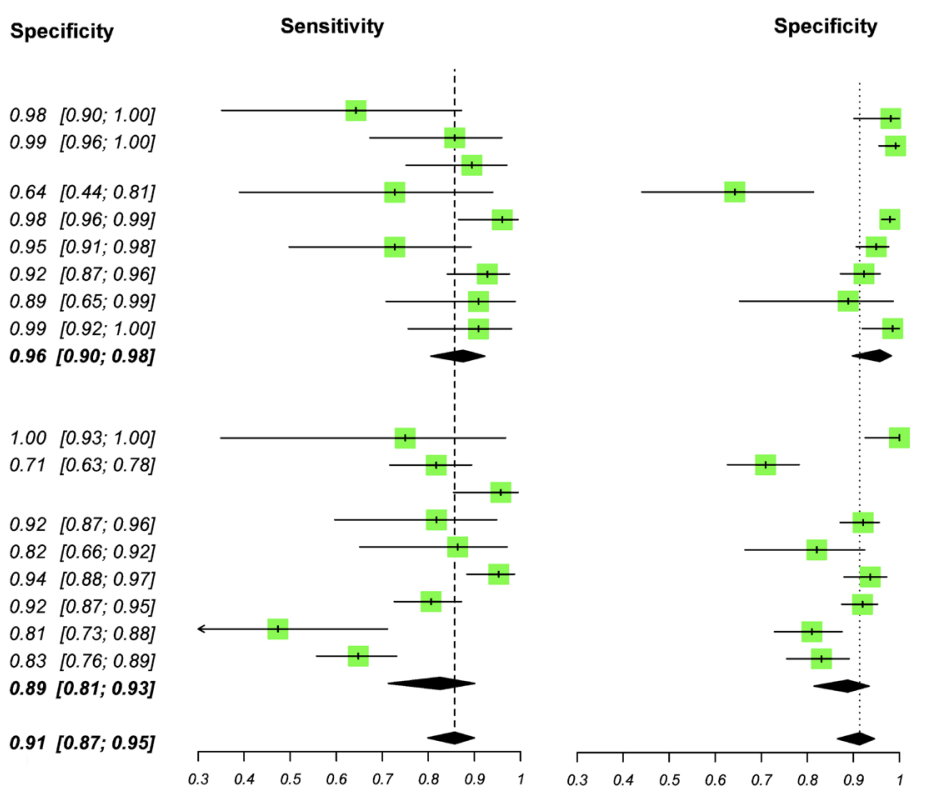

\section{Dilatation}

Study and Subgroup

Experienced

Biais 2012

Coletta 2006

Gulic (exp) 2016

Khan 2014

Liebo (expDR) 2011

Liebo (expMS) 2011

Xie 2006

Random effects model

Inexperienced

Giusca 2010

Gulic (inexp) 2016

Kobal 2005

Liebo (inexpML) 2011

Liebo (inexpRI) 2011

Lopez-Palmero 2015

Ruddox 2013

Random effects model

Sensitivity

$1.00[0.63 ; 1.00]$

$1.00[0.96 ; 1.00]$

$0.44[0.14 ; 0.79]$

$0.88[0.72 ; 0.97]$

$0.67[0.38 ; 0.88]$

$0.64[0.35 ; 0.87]$

$0.89[0.67 ; 0.99]$

$0.89[0.64 ; 0.97]$

$0.71 \quad[0.29 ; 0.96]$

$0.56[0.21 ; 0.86]$

$0.67[0.35 ; 0.90]$

$0.53[0.27 ; 0.79]$

$0.73[0.45 ; 0.92]$

$0.94[0.80 ; 0.99]$

$0.46[0.32 ; 0.61]$

$0.68[0.51 ; 0.81]$

Fixed effects (plural) model $0.73[0.59 ; 0.84]$
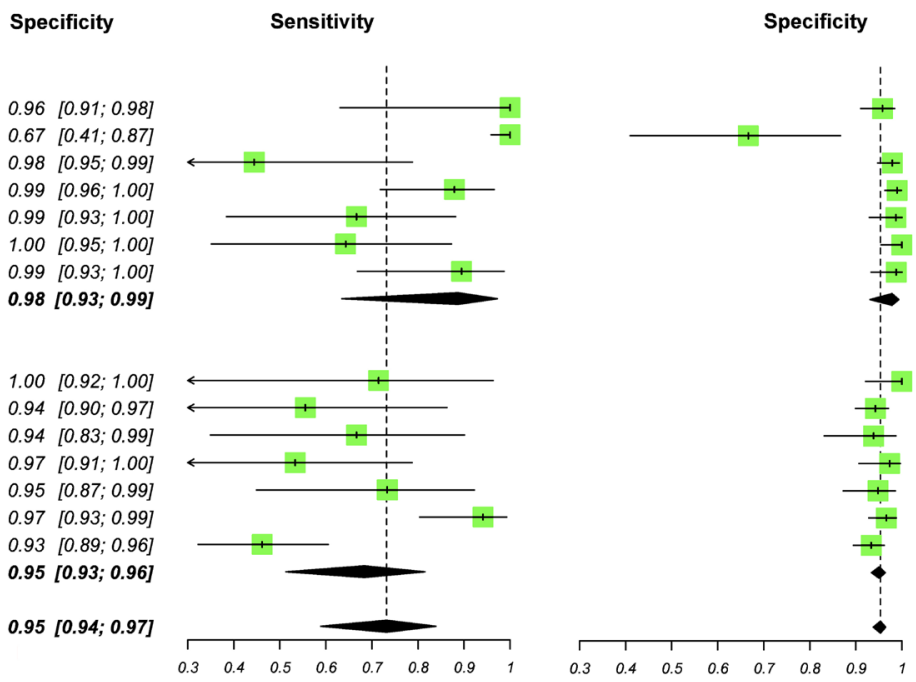

Figure 2 Meta-analyses of left ventricular ejection fraction (LVEF) and left ventricular (LV) dilatation. Sensitivity and specificity ( $95 \%$ Cl) values are reported.

does not completely explain the differences between studies. This apparent heterogeneity can also be observed in the SROC curves for LVEF, WMA and LV dilatation. The increased heterogeneity in the sensitivity plots may be partly explained by fewer patients with the target condition than without. This provides less certainty and results in wider CIs.

A negative correlation between sensitivity and specificity was shown in the meta-analysis of LVEF $<45 \%$, WMA and LV dilatation indicating no significant heterogeneity. The correlation coefficients for LVEF (any abnormality) and LVH was positive indicating the presence of possible heterogeneity in the results. We planned to assess the effect of operator experience, pre-existing comorbidities and baseline LV function on the results in a meta-regression covariate analysis. However, only operator experience was sufficiently reported and showed that experience was a significant factor in detecting LVEF, WMA and LV dilatation.

Variation in thresholds likely accounts for some heterogeneity when measuring LVEF (any abnormality), LV dilatation and LVH. Studies with both qualitative and quantitative methodologies were incorporated into the meta-analysis. Quantitative thresholds of $\mathrm{LV}$ dilatation ranged from $>53 \mathrm{~mm}$ to $>59 \mathrm{~mm}$, with some studies classifying LV dilatation subject to gender. Similarly, studies measuring LVH were both qualitative and quantitative, with thresholds ranging from $>10 \mathrm{~mm}$ to $>12$ $\mathrm{mm}$. A sensitivity analysis excluding qualitative assessment of $\mathrm{LVH}$ and LV dilatation showed an improvement in the diagnostic accuracy (online supplemental table 3).

Other sources of heterogeneity may also exist that cannot be assessed including functionality and technological advancement 
WMA

Study and Subgroup
Experienced
Cullen 2013
Fedson 2003
Khan 2014
Liebo (expDR) 2011
Liebo (expMS) 2011
Vignon 2004
Wejner-Mik 2019
Xie 2006
Random effects model
Inexperienced
Bruce 2002
Decara (inexp) 2003
Giusca 2010
Liebo (inexpML) 2011
Liebo (inexpRI) 2011
Lucas 2009
Lucas 2011
Ruddox 2013
Random effects model
Fixed effects (plural) model

Fixed effects (plural) model

$\begin{array}{ll}\text { Sensitivity } & \text { Specificity } \\ & \\ 0.60[0.32 ; 0.84] & 0.95[0.90 ; 0.98] \\ & 0.90[0.76 ; 0.97] \\ 0.86[0.78 ; 0.92] & 0.97[0.93 ; 0.99] \\ 0.67[0.35 ; 0.90] & 0.91[0.82 ; 0.96] \\ 0.82[0.48 ; 0.98] & 0.94[0.85 ; 0.98] \\ 0.90[0.70 ; 0.99] & 1.00[0.16 ; 1.00] \\ 0.88[0.76 ; 0.95] & 0.97[0.85 ; 1.00] \\ 0.97[0.85 ; 1.00] & 0.98[0.92 ; 1.00] \\ \mathbf{0 . 8 5}[0.76 ; 0.91] & 0.95[0.93 ; 0.96] \\ & \\ & \\ 0.88[0.79 ; 0.93] & 0.81[0.62 ; 0.94] \\ 0.55[0.32 ; 0.77] & \\ 0.65[0.43 ; 0.84] & 0.90[0.73 ; 0.98] \\ 0.60[0.26 ; 0.88] & 0.94[0.86 ; 0.98] \\ 0.80[0.44 ; 0.97] & 0.85[0.74 ; 0.92] \\ 0.85[0.75 ; 0.92] & 0.88[0.83 ; 0.92] \\ 0.84[0.73 ; 0.92] & 0.85[0.78 ; 0.91] \\ 0.76[0.66 ; 0.84] & 0.88[0.82 ; 0.92] \\ \mathbf{0 . 7 8}[0.70 ; 0.84] & 0.88[0.85 ; 0.90] \\ & \\ 0.81[0.74 ; 0.85] & 0.90[0.88 ; 0.92]\end{array}$

Sensitivity

$0.77[0.56 ; 0.91]$ $0.98[0.91 ; 1.00]$ $1.00[0.03 ; 1.00]$ $0.82[0.69 ; 0.91]$

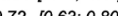
$0.80[0.65 ; 0.91]$ $0.85[0.72 ; 0.92]$

$0.56[0.21 ; 0.86]$ $0.83[0.75 ; 0.90]$ $0.65[0.43 ; 0.84]$ $0.96[0.91 ; 0.98]$ $0.70[0.51 ; 0.84]$ $0.70[0.51 ; 0.84]$ $1.00[0.81 ; 1.00]$ $0.80[0.61 ; 0.91]$

$0.83[0.73 ; 0.90]$

Specificity
$0.97[0.92 ; 0.99]$
$0.78[0.56 ; 0.93]$
$0.96[0.94 ; 0.98]$
$0.75[0.65 ; 0.83]$
$0.93[0.84 ; 0.98]$
$0.91[0.82 ; 0.96]$

$1.00[0.92 ; 1.00]$
$0.59[0.48 ; 0.69]$
$0.71[0.54 ; 0.85]$
$0.91[0.82 ; 0.96]$
$0.73[0.67 ; 0.78]$
$0.68[0.61 ; 0.75]$
$0.99[0.92 ; 1.00]$
$0.87[0.67 ; 0.96]$
$0.90[0.82 ; 0.95]$

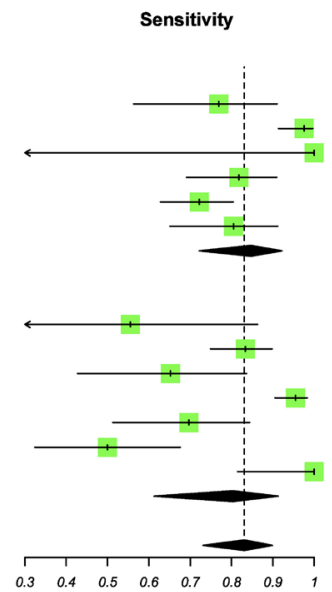

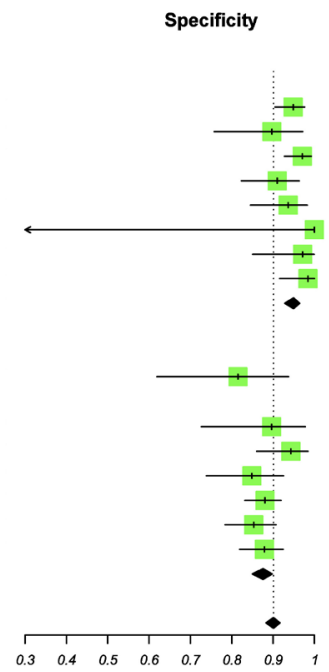

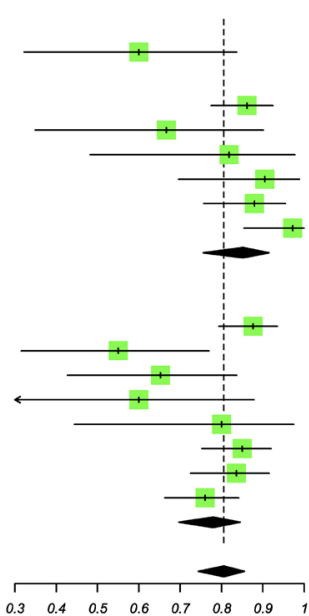

$\begin{array}{llllllll}0.3 & 0.4 & 0.5 & 0.6 & 0.7 & 0.8 & 0.9 & 1\end{array}$

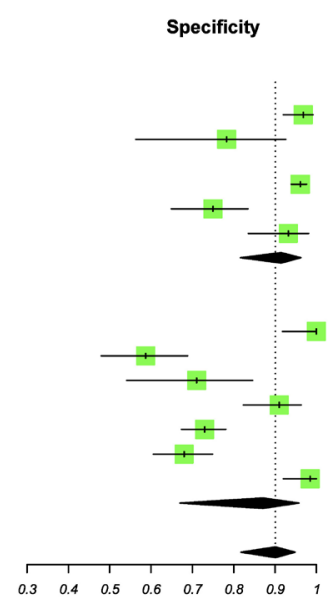

Figure 3 Meta-analyses of wall motion abnormality (WMA) and left ventricular hypertrophy (LVH). Sensitivity and specificity (95\% CI) values are reported.

of handheld devices that may allow for more accurate results to be obtained. Some studies reported any abnormality in LVEF as a positive finding without quantifying the results into mild, moderate or severe, which may have led to heterogeneity between studies. However, to limit the effect of the possible heterogeneity we analysed studies reporting LVEF $<45 \%$ (moderate and severe degrees of LV dysfunction) separately. This analysis allowed for a detailed assessment of HUD in significant disease.

Varying levels of experience using HUD by experienced echocardiographers may account for some heterogeneity. The level and volume of training received by non-experienced users prior to each study was also variable adding to heterogeneity within the non-experienced subgroup.

\section{DISCUSSION}

To the best of our knowledge, this is the first meta-analysis of the diagnostic accuracy of HUD for imaging LV cardiac structural and functional abnormalities and the first to report the impact of user experience. The meta-analysis shows that HUD is both a sensitive and specific method for assessing LV function and morphology when performed by experienced operators. While a basic competence in HUD can be achieved in a relatively short period of time, in clinical practice, a cautious, supervised approach should be applied when inexperienced users are acquiring and interpreting images. This mostly applies to secondary care where the prevalence of disease and the availability of experienced echocardiographers is greatest. Our findings demonstrate that HUD is a valuable bedside tool that can be used to identify those who require further investigation and as a result may lead to a reduction in the number of unnecessary echo referrals (table 3 ).

Training is required to be able to use HUD competently and therefore the results of our study should be interpreted based on the level of operator experience. The amount of training offered and ability to practise using HUD will also impact the diagnostic outcome that can be expected. Operators with limited training however were less able to detect LV dilatation and WMA, recording pooled sensitivities of $68 \%$ and $78 \%$, respectively compared with $89 \%$ and $85 \%$ achieved by experienced echocardiographers. A positive scan in an experienced hand had a 3-6 times higher odds of showing true LV impairment, LV dilatation or WMA compared with inexperienced operators. Operator experience was not a significant discriminating factor when measuring LVH suggesting that it can be more accurately measured by clinicians with minimal training. 

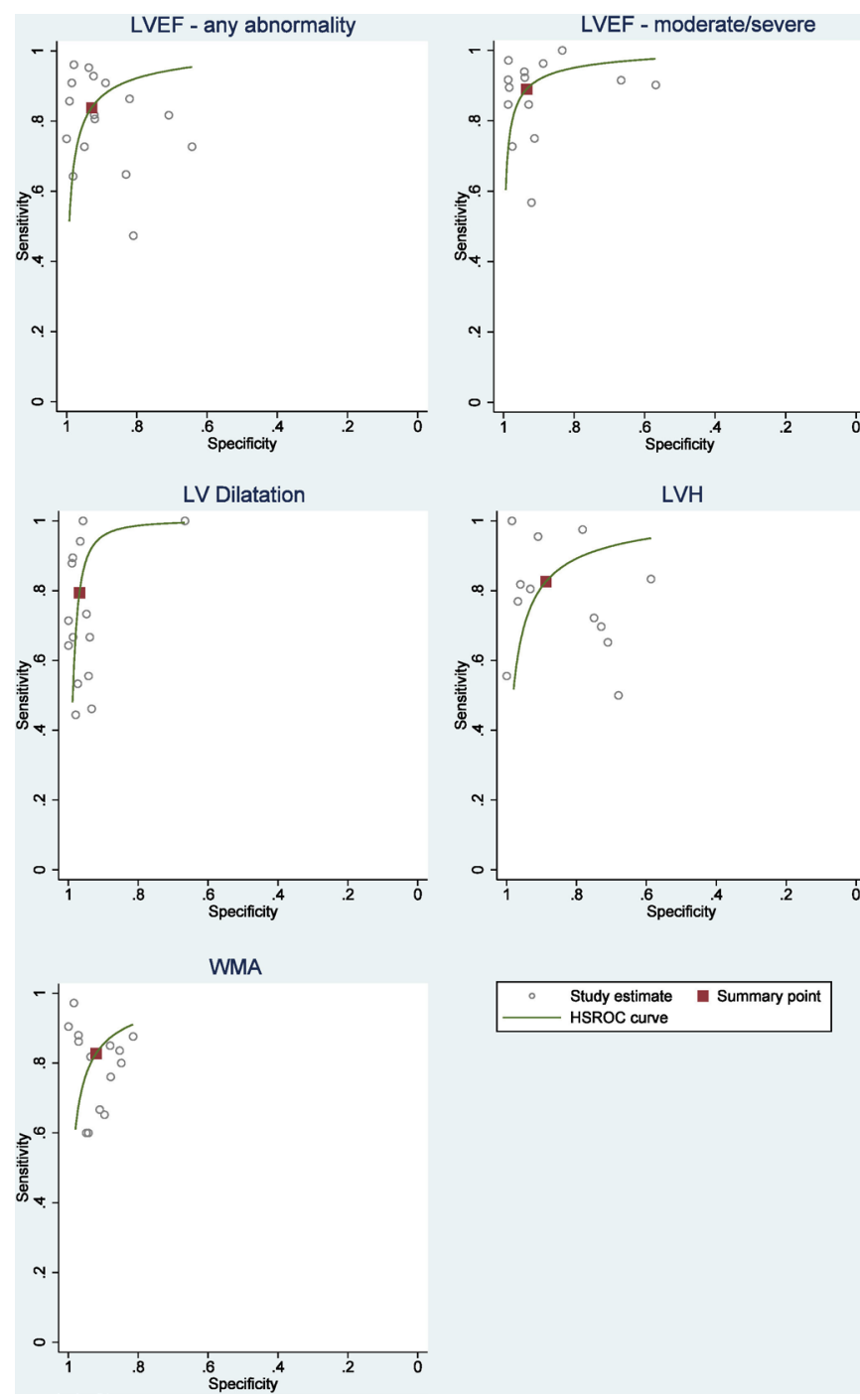

Figure 4 Summary receiver operating characteristic curve (SROC) for the pooled sensitivity and specificity with the summary point for the different handheld ultrasound devices assessments. HSROC, hierarchical summary receiver operator curves; LVEF, left ventricular ejection fraction; LVH, left ventricular hypertrophy; LV, left ventricular; WMA, wall motion abnormality.

Important logistical points need to be considered including cost-effectiveness, training and accessibility by clinicians. HUD has been shown to be more cost-effective in comparison to TTE and reduces overall costs when compared with physical examination. ${ }^{6} 11$ Despite these potential savings, implementation requires training and frequent revalidation to maintain the clinician's skill. Didactic and practical sessions are required before clinicians can achieve basic competence in HUD. A minimum of 30 scans has been recommended, however brief training is associated with an increased false-positive rate. ${ }^{12} 13$ This first highlights that HUD performed by inexperienced users should be supervised by experienced echocardiographers as previously mentioned and second, the importance of frequent training and consolidation in echocardiography before allowing users to image patients without supervision. Accessibility of recorded images is therefore a fundamental property of a HUD if sufficient supervision is to be achieved.

Our data suggest that HUD is best positioned at the beginning of the clinical pathway when suspicious of cardiac pathology,
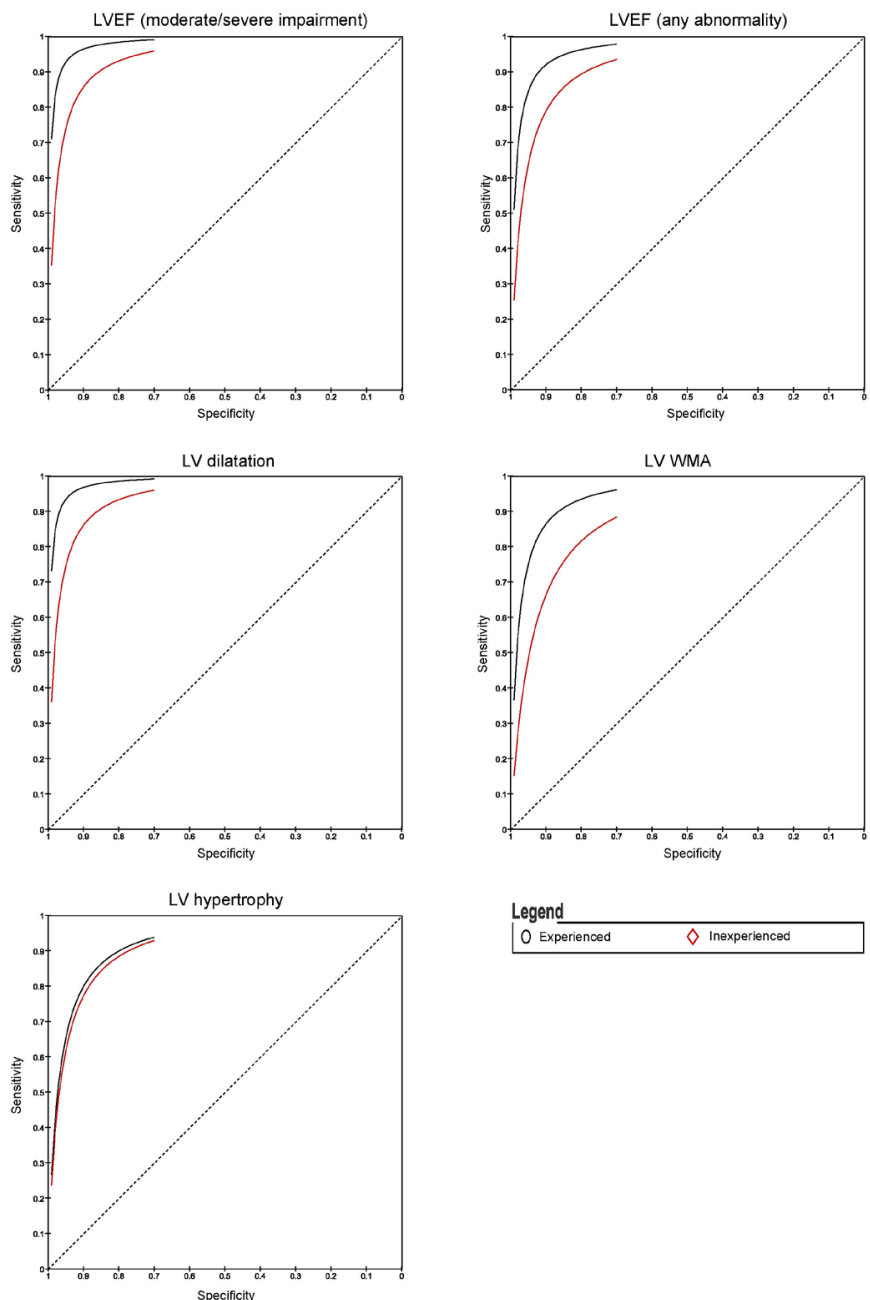

Legend

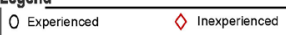

Figure 5 Summary receiver operating characteristic curves for LV parameters comparing effect user experience on handheld ultrasound devices diagnostic accuracy. LVEF, left ventricular ejection fraction; LV, left ventricular; WMA, wall motion abnormality.

thus augmenting the cardiovascular examination. Detecting cardiac disease earlier, when the prevalence of any abnormality is at its lowest, is likely to incur higher rates of false positives. However, HUD should be considered as a method of triaging patients who may require further investigation. HUD should not be considered as a replacement to TTE. HUD can be conducted at the bedside and take $<6$ min. ${ }^{14}$ It can be argued that this is preferable compared with the potential of unnecessarily having to wait for a more complex scan, which may require the patient to return on a separate day or result in a longer stay in hospital. However, a negative finding on HUD and not proceeding to full TTE risks cardiac abnormalities being missed, a factor which should be considered on an individual patient basis.

Negative results (ie, specificity) can be used with reasonable confidence used to determine normal cardiac physiology. However, positive results need to be interpreted with caution, especially when performed by inexperienced HUD users. Clinical decision making should not be solely guided by the interpretation of HUD images, even by experienced echocardiographers. Instead, these results suggest that HUD should act as an initial diagnostic test to aid decision making on whether further investigation, including TTE, and treatment is required.

Given the excellent sensitivity and specificity particularly seen with more experienced operators, it is likely that the role of 
Table 2 Results of meta-analyses comparing the diagnostic accuracy of HUD with first-line TTE

\begin{tabular}{|c|c|c|c|c|c|c|c|c|c|}
\hline \multicolumn{10}{|l|}{ HUD compared with TTE } \\
\hline \multirow[b]{2}{*}{ Sensitivity $\%$} & \multicolumn{3}{|l|}{ Total } & \multicolumn{3}{|c|}{ Experienced } & \multicolumn{3}{|c|}{ Inexperienced } \\
\hline & Studies (n) & Prevalence & $\begin{array}{l}\text { Sensitivity }(95 \% \\
\mathrm{Cl})\end{array}$ & Studies (n) & Prevalence & $\begin{array}{l}\text { Sensitivity }(95 \% \\
\mathrm{Cl})\end{array}$ & Studies (n) & Prevalence & $\begin{array}{l}\text { Sensitivity } \\
(95 \% \mathrm{Cl})\end{array}$ \\
\hline LVEF (any abnormality) & 15 (2936) & 0.23 & 86 (80 to 90$)$ & 9 (1406) & 0.18 & 88 (81 to 92$)$ & $9(1530)$ & 0.28 & 83 (71 to 90$)$ \\
\hline LVEF (moderate/severe) & $10(1611)$ & 0.27 & 91 (86 to 94$)$ & $5(722)$ & 0.27 & 93 (89 to 96$)$ & 7 (889) & 0.27 & 84 (72 to 92$)$ \\
\hline WMA & $13(1931)$ & 0.27 & 81 (74 to 85$)$ & $6(794)$ & 0.26 & 85 (76 to 91$)$ & $7(1137)$ & 0.28 & 78 (70 to 84$)$ \\
\hline LV dilatation & 10 (1966) & 0.13 & 73 (59 to 84$)$ & $6(966)$ & 0.17 & 89 (64 to 97$)$ & $6(1000)$ & 0.09 & 68 (51 to 81$)$ \\
\hline LVH & $12(2229)$ & 0.24 & $83(73$ to 90$)$ & $6(1096)$ & 0.23 & 85 (72 to 92$)$ & $7(1133)$ & 0.26 & 80 (61 to 91$)$ \\
\hline LVEF (any abnormality) & $14(2851)$ & 0.21 & 91 (87 to 95$)$ & $8(1368)$ & 0.16 & 96 (90 to 98$)$ & $8(1483)$ & 0.26 & 89 (81 to 93 ) \\
\hline LVEF (moderate/severe) & 10 (1611) & 0.27 & 92 (87 to 96$)$ & $5(722)$ & 0.27 & 96 (87 to 99$)$ & $7(889)$ & 0.27 & 91 (83 to 95$)$ \\
\hline WMA & 12 (1876) & 0.28 & 90 (88 to 92 ) & $6(759)$ & 0.27 & 95 (93 to 96$)$ & $6(1117)$ & 0.28 & 88 (85 to 90$)$ \\
\hline LV dilatation & 10 (1966) & 0.13 & 95 (94 to 97 ) & $6(966)$ & 0.17 & 98 (93 to 99$)$ & $6(1000)$ & 0.09 & 95 (93 to 96 ) \\
\hline LVH & $11(2228)$ & 0.25 & 90 (82 to 95 ) & $5(1095)$ & 0.23 & 91 (82 to 96 ) & 7 (1133) & 0.26 & 87 (67 to 96 ) \\
\hline
\end{tabular}

HUD, handheld ultrasound devices; LV, left ventricular; LVEF, LV ejection fraction; LVH, LV dilatation and hypertrophy; TTE, transthoracic echocardiography; WMA, wall motion abnormalities.

HUD will become even more prominent in future clinical practice. We would support earlier teaching and training of HUD and its incorporation into the medical school curriculum, thus providing an important way of ensuring adequate training for all future doctors.

\section{Strengths and limitations}

An extensive literature search was performed. No search filters were used revealing results from an unpublished source, thus minimising the risk of publication bias. To limit the effect of any reporting bias, data were carefully extracted from the results of some studies that did not explicitly state sensitivity and specificity values. The search and data extraction were performed by two authors independently to minimise the bias in the review process.

Half of the included studies are $>10$ years old and improvement in screen technology, image processing and other advancements might play a pivotal role in improving the diagnostic accuracy of HUD.

The lack of a common threshold for WMA, LV dilatation and LVH means the diagnostic performance may vary between centres. Our results do however show that despite variation in thresholds, the specificity of HUD remains $\geq 87 \%$ for all characteristics. Even if sensitivity is reduced, the use of HUD as an initial diagnostic tool means diagnosing a condition and determining disease severity is not the aim of this test. Any uncertainty when interpreting the image should result in referral for further investigation. Clinical suspicion of HF and measurement of LV filling pressures is an important indication for echocardiography assessment and would be a valuable bedside tool. Clarius is one of the only scanners on the market capable of pulse-wave Doppler (PWD), permitted by the installation of a liquid heating device which prevents overheating. ${ }^{15}$ The current technological capabilities of most HUDs do not include PWD and therefore filling pressures cannot be measured using these devices. ${ }^{16}$ We were therefore unable to analyse sufficient data regarding this variable.

\section{Future applications}

With advancement of technology, LV border tracking and other methods of automatic, device-generated, quantitative measures of ejection fraction may become routinely available. ${ }^{17}$ Incorporation of PWD and continuous-wave Doppler technology into a greater number of available HUDs will also allow for a more extensive range of quantitative cardiovascular assessments to be undertaken at the bedside. Qualitative assessment of valvular heart disease using colour-flow Doppler is available on most HUDs, however is outside the scope of this review. Images may ultimately be sent remotely following acquisition directly to an experienced echocardiographer who can review and interpret images immediately, fast-tracking patients who require further investigation. $^{18}{ }^{19}$ Further developments in HUD therefore

Table 3 Summary of findings

\begin{tabular}{|c|c|c|c|c|}
\hline Review question & \multicolumn{4}{|c|}{ Is handheld echocardiography able to accurately diagnose LV dysfunction compared with TTE? } \\
\hline Population & \multicolumn{4}{|c|}{6062 participants aged $65 \pm 5$ years with a male predominance of $54 \%$ requiring routine referral for TTE } \\
\hline Setting & \multicolumn{4}{|c|}{ Single centres with access to TTE } \\
\hline Studies & \multicolumn{4}{|c|}{ Studies of diagnostic tests } \\
\hline Quality of evidence & \multicolumn{4}{|c|}{ Majority of studies reported consecutive or random sampling, blinding of assessors and short time between HUD and TTE imaging (24-28 hours) } \\
\hline \multirow[t]{2}{*}{ Pooled results } & \multicolumn{2}{|c|}{ Sensitivity $(95 \% \mathrm{Cl})$} & \multicolumn{2}{|c|}{ Specificity $(95 \% \mathrm{Cl})$} \\
\hline & Experienced & Inexperienced & Experienced & Inexperienced \\
\hline LVEF (any abnormality) & 88 (81 to 92$)$ & 83 (71 to 90$)$ & 96 (90 to 98 ) & 89 (81 to 93 ) \\
\hline LVEF (moderate/severe) & 93 (89 to 96$)$ & 84 (72 to 92$)$ & 96 (87 to 99) & 91 (83 to 95$)$ \\
\hline WMA & 85 (76 to 91$)$ & 78 (70 to 84$)$ & 95 (93 to 96$)$ & 88 (85 to 90$)$ \\
\hline LV dilatation & 89 (64 to 97) & 68 (51 to 81$)$ & 98 (93 to 99 ) & 95 (93 to 96$)$ \\
\hline LVH & 85 (72 to 92$)$ & 80 (61 to 91 ) & 91 (82 to 96$)$ & 87 (67 to 96 ) \\
\hline
\end{tabular}

HUD, handheld ultrasound devices; LV, left ventricular; LVEF, LV ejection fraction; LVH, LV dilatation and hypertrophy; TTE, transthoracic echocardiography; WMA, wall motion abnormalities. 
have the potential to revolutionise the bedside cardiovascular examination.

This study highlights the need to further develop methods to bridge the gap between experienced and inexperienced users. Education and introduction of an ultrasound curriculum for medical students and junior doctors can improve understanding of clinical anatomy, develop basic ultrasound skills and later their diagnostic ability. ${ }^{20} 21$ Formulation of a designated HUD training pathway would allow for standardisation of HUD competencies and provide structure to those wishing to advance their experience using HUDs. These suggestions are limited by the financial burden this would incur as well as a shortfall of clinicians adequately trained using HUDs.

\section{CONCLUSION}

This meta-analysis supports the use of HUD as a powerful modality for predicting LV size and systolic function. HUD diagnostic yield is superior when performed by experienced echocardiographers. Images acquired by an inexperienced operator should be done under direct supervision or validated by a more experienced user. This study provides a strong rationale for considering HUD as an auxiliary tool to the physical examination in secondary care, to aid the clinical decision making when considering referral for TTE.

\section{Key messages}

What is already known on this subject?

- Handheld cardiac ultrasound device (HUD) offers rapid bedside assessment of cardiac morphology and function.

- The diagnostic accuracy of HUD previously reported has shown heterogeneity between studies and its clinical value has yet to be determined.

\section{What might this study add?}

- To the best of our knowledge, this is the first study to perform a meta-analysis evaluating the diagnostic accuracy of HUD devices to detect cardiac dysfunction and the impact of operator experience on test accuracy.

- This study reports that HUD test accuracy is significantly improved when performed by experienced operators.

\section{How might this impact on clinical practice?}

- The clinical utility of HUD is rapidly expanding.

- Augmentation of the physical cardiovascular examination using HUD may improve detection of cardiac size and function at the bedside and lead to a reduction in the number of unnecessary departmental transthoracic echocardiography referrals.

- Image interpretation by inexperienced operators should be confirmed by more experienced echocardiographers before clinical decisions and referral for further imaging are made.

\section{Author affiliations}

Department of Infection, Immunity and Cardiovascular Disease, The University of Sheffield, Sheffield, UK

${ }^{2}$ Cardiovascular and Metabolic Health, Academic Unit of Radiology, University of Sheffield, Sheffield, UK

${ }^{3}$ Cardiology, Norfolk and Norwich University Hospital NHS Trust, Norwich, UK ${ }^{4}$ Cardiology, Wessex Cardiothoracic Centre, University Hospital Southampton, Southampton, UK

LICAMM, University of Leeds, Leeds, UK

${ }^{6}$ Department of Cardiology, Royal Brompton Hospital, London, UK

${ }^{7}$ Vrije Universiteit Amsterdam, Amsterdam, The Netherlands

${ }^{8}$ Second Floor, Norwich Medical School, University of East Anglia, Norwich, UK
Twitter Samer Alabed @smrabd and Peter Swoboda @pswoboda81

Contributors SJ, SA and PG contributed to the study conception and design. Material preparation, data collection and analysis were performed by SJ, SA and PG. SA performed the meta-analysis of the diagnostic accuracy parameters. All authors contributed to the interpretation of data. The first draft of the manuscript was written by SJ and all authors commented on previous versions of the manuscript. All authors read and approved the final manuscript.

Funding This work was funded in part by the Wellcome Trust (215799/Z/19/Z, $214567 / Z / 18 / Z$ and 205188/Z/16/Z). For the purpose of Open Access, the authors have applied a CC BY public copyright licence to any Author Accepted Manuscript version arising from this submission.

Competing interests PG is an advisor for Pie Medical Imaging and Medis Medical Imaging. JW lists commercial relationships with AstraZeneca, Bayer and Novartis.

Patient consent for publication Not required.

Provenance and peer review Not commissioned; externally peer reviewed.

Data availability statement All data relevant to the study are included in the article or uploaded as supplementary information.

Supplemental material This content has been supplied by the author(s) It has not been vetted by BMJ Publishing Group Limited (BMJ) and may not have been peer-reviewed. Any opinions or recommendations discussed are solely those of the author(s) and are not endorsed by BMJ. BMJ disclaims all liability and responsibility arising from any reliance placed on the content. Where the content includes any translated material, BMJ does not warrant the accuracy and reliability of the translations (including but not limited to local regulations, clinical guidelines, terminology, drug names and drug dosages), and is not responsible for any error and/or omissions arising from translation and adaptation or otherwise.

Open access This is an open access article distributed in accordance with the Creative Commons Attribution 4.0 Unported (CC BY 4.0) license, which permits others to copy, redistribute, remix, transform and build upon this work for any purpose, provided the original work is properly cited, a link to the licence is given, and indication of whether changes were made. See: https://creativecommons.org/ licenses/by/4.0/.

\section{ORCID iDs}

Sam Jenkins http://orcid.org/0000-0003-1941-2892

Samer Alabed http://orcid.org/0000-0002-9960-7587

Benoy Nalin Shah http://orcid.org/0000-0001-9681-7311

Roxy Senior http://orcid.org/0000-0001-6579-7039

Vassilios S Vassiliou http://orcid.org/0000-0002-4005-7752

\section{REFERENCES}

1 Indications for echocardiography.pdf. Available: https://www.bsecho.org/common/ Uploaded\%20files/Education/Protocols\%20and\%20guidelines/Indications\%20for\% 20echocardiography.pdf [Accessed 19 Feb 2021].

2 Mitchell C, Rahko PS, Blauwet LA, et al. Guidelines for performing a comprehensive transthoracic echocardiographic examination in adults: recommendations from the American Society of echocardiography. J Am Soc Echocardiogr 2019;32:1-64.

3 Sicari R, Galderisi M, Voigt J-U, et al. The use of pocket-size imaging devices: a position statement of the European association of echocardiography. Eur J Echocardiogr 2011;12:85-7.

4 Wharton G, Steeds R, Allen J, et al. A minimum dataset for a standard adult transthoracic echocardiogram: a guideline protocol from the British Society of echocardiography. Echo Res Pract 2015;2:G9-24.

5 Bhavnani SP, Narula J, Sengupta PP. Mobile technology and the digitization of healthcare. Eur Heart J 2016;37:1428-38.

6 Pathan F, Fonseca R, Marwick TH. Usefulness of Hand-Held Ultrasonography as a Gatekeeper to Standard Echocardiography for "Rarely Appropriate" Echocardiography Requests. Am J Cardiol 2016;118:1588-92.

7 Diagnostic test accuracy (DTA) reviews. Available: https://training.cochrane.org/ diagnostic-test-accuracy-dta-reviews [Accessed 6 Jul 2021].

8 Galasko GIW, Lahiri A, Senior R. Portable echocardiography: an innovative tool in screening for cardiac abnormalities in the community. Eur J Echocardiogr 2003;4:119-27.

9 Bruce CJ, Montgomery SC, Bailey KR, et al. Utility of hand-carried ultrasound devices used by cardiologists with and without significant echocardiographic experience in the cardiology inpatient and outpatient settings. Am J Cardio/ 2002;90:1273-5.

10 Greaves K, Jeetley P, Hickman M, et al. The use of hand-carried ultrasound in the hospital setting--a cost-effective analysis. J Am Soc Echocardiogr 2005;18:620-5.

11 Spencer KT, Kimura BJ, Korcarz CE, et al. Focused cardiac ultrasound: recommendations from the American Society of echocardiography. J Am Soc Echocardiogr 2013;26:567-81. 
12 Wilkinson JS, Barake W, Smith C, et al. Limitations of condensed teaching strategies to develop hand-held cardiac ultrasonography skills in internal medicine residents. Can J Cardiol 2016;32:1034-7.

13 Stokke TM, Ruddox V, Sarvari SI, et al. Brief group training of medical students in focused cardiac ultrasound may improve diagnostic accuracy of physical examination. J Am Soc Echocardiogr 2014;27:1238-46.

14 Hammoudi N, Arangalage D, Boubrit L, et al. Ultrasound-based teaching of cardiac anatomy and physiology to undergraduate medical students. Arch Cardiovasc Dis 2013;106:487-91.

15 Mjolstad OC, Dalen H, Graven T, et al. Routinely adding ultrasound examinations by pocket-sized ultrasound devices improves inpatient diagnostics in a medical department. Eur J Intern Med 2012;23:185-91.

16 C3 Overview - Handheld Curvilinear Ultrasound Scanner - Clarius. Available: https:// clarius.com/gb/scanners/c3/ [Accessed 24 May 2021].

17 Rykkje A, Carlsen JF, Nielsen MB. Hand-Held ultrasound devices compared with High-End ultrasound systems: a systematic review. Diagnostics 2019;9. doi:10.3390/ diagnostics9020061. [Epub ahead of print: 1506 2019].

18 Narula S, Shameer K, Salem Omar AM, et al. Machine-Learning algorithms to Automate morphological and functional assessments in 2D echocardiography. J Am Coll Cardiol 2016;68:2287-95.

19 Sengupta PP, Narula N, Modesto K, et al. Feasibility of intercity and trans-atlantic telerobotic remote ultrasound: assessment facilitated by a nondedicated bandwidth connection. JACC Cardiovasc Imaging 2014;7:804-9.

20 Boman $\mathrm{K}$, Olofsson $\mathrm{M}$, Berggren $\mathrm{P}$, et al. Robot-assisted remote echocardiographic examination and teleconsultation: a randomized comparison of time to diagnosis with standard of care referral approach. JACC Cardiovasc Imaging 2014;7:799-803.

21 Aldaas OM, Igata S, Raisinghani A, et al. Accuracy of left ventricular ejection fraction determined by automated analysis of handheld echocardiograms: a comparison of experienced and novice examiners. Echocardiography 2019;36:2145-51.

22 Alexander JH, Peterson ED, Chen AY, et al. Feasibility of point-of-care echocardiography by internal medicine house staff. Am Heart J 2004;147:476-81.

23 Andersen GN, Haugen BO, Graven T, et al. Feasibility and reliability of point-of-care pocket-sized echocardiography. Eur J Echocardiogr 2011;12:665-70.

24 Biais M, Carrié C, Delaunay F, et al. Evaluation of a new pocket echoscopic device for focused cardiac ultrasonography in an emergency setting. Crit Care 2012;16:R82.

25 Coletta C, De Marchis E, Lenoli M, et al. Reliability of cardiac dimensions and valvular regurgitation assessment by sonographers using hand-carried ultrasound devices. Eur J Echocardiogr 2006;7:275-83.

26 Cullen MW, Blauwet LA, Vatury OM, et al. Diagnostic capability of comprehensive handheld vs transthoracic echocardiography. Mayo Clin Proc 2014;89:790-8.

27 DeCara JM, Lang RM, Koch R, et al. The use of small personal ultrasound devices by internists without formal training in echocardiography. Eur J Echocardiogr 2003:4:141-7.

28 Fedson S, Neithardt G, Thomas P, et al. Unsuspected clinically important findings detected with a small portable ultrasound device in patients admitted to a general medicine service. J Am Soc Echocardiogr 2003;16:901-5.

29 Ghani SN, Kirkpatrick JN, Spencer KT, et al. Rapid assessment of left ventricular systolic function in a pacemaker clinic using a hand-carried ultrasound device. J Interv Card Electrophysiol 2006;16:39-43.

30 Giusca S, Jurcut R, Ticulescu R, et al. Accuracy of handheld echocardiography for bedside diagnostic evaluation in a tertiary cardiology center: comparison with standard echocardiography. Echocardiography 2011;28:136-41.

31 Gulič TG, Makuc J, Prosen G, et al. Pocket-size imaging device as a screening tool for aortic stenosis. Wien Klin Wochenschr 2016;128:348-53.

32 Khan HA, Wineinger NE, Uddin PQ. Can Hospital rounds with pocket echocardiography by cardiologists reduce standard transthoracic echocardiography? Am J Med 2014;127:669.e1-669.e7. doi:10.1016/j.amimed.2014.03.015
33 Kirkpatrick JN, Ghani SN, Spencer KT. Hand carried echocardiography screening for LV systolic dysfunction in a pulmonary function laboratory. Eur J Echocardiogr 2008;9:381-3. doi:10.1016/j.euje.2007.06.013

34 Kobal SL, Trento L, Baharami S, et al. Comparison of effectiveness of handcarried ultrasound to bedside cardiovascular physical examination. Am J Cardiol 2005;96:1002-6.

35 Liebo MJ, Israel RL, Lillie EO. Pocket mobile echocardiography: the next-generation stethoscope? A comparison of rapidly acquired PME images to standard TTE. Ann Intern Med 2011;155:33-8. doi:10.7326/0003-4819-155-1-201107050-00005

36 López-Palmero S, Bolivar-Herrera N, López-Lloret G, et al. Diagnostic utility of handheld ultrasonography as an extension of the physical examination of patients with heart failure. Rev Clin Esp 2015;215:204-10.

37 Lucas BP, Candotti C, Margeta B, et al. Diagnostic accuracy of hospitalist-performed hand-carried ultrasound echocardiography after a brief training program. J Hosp Med 2009;4:340-9. doi:10.1002/jhm.438

38 Lucas BP, Candotti C, Margeta B, et al. Hand-Carried echocardiography by hospitalists: a randomized trial. Am J Med 2011;124:766-74

39 Martin LD, Howell EE, Ziegelstein RC, et al. Hand-carried ultrasound performed by hospitalists: does it improve the cardiac physical examination? Am J Med 2009;122:35-41.

40 Mehta M, Jacobson T, Peters D, et al. Handheld ultrasound versus physical examination in patients referred for transthoracic echocardiography for a suspected cardiac condition. JACC Cardiovasc Imaging 2014;7:983-90.

41 Mjølstad OC, Andersen GN, Dalen H, et al. Feasibility and reliability of point-of-care pocket-size echocardiography performed by medical residents. Eur Heart J CardiovasC Imaging 2013;14:1195-202.

42 Nilsson G, Söderström L, Alverlind K, et al. Hand-Held cardiac ultrasound examinations performed in primary care patients by nonexperts to identify reduced ejection fraction. BMC Med Educ 2019;19:282.

43 Olesen LL, Andersen A, Thaulow S. Hand-Held echocardiography is useful for diagnosis of left systolic dysfunction in an elderly population. Dan Med $J$ 2015;62:A5100

44 Perez-Avraham G, Kobal SL, Etzion 0, et al. Left ventricular geometric abnormality screening in hypertensive patients using a hand-carried ultrasound device. J Clin Hypertens 2010:12:181-6.

45 Razi R, Estrada JR, Doll J, et al. Bedside hand-carried ultrasound by internal medicine residents versus traditional clinical assessment for the identification of systolic dysfunction in patients admitted with decompensated heart failure. J Am Soc Echocardiogr 2011:24:1319-24.

46 Ruddox V, Stokke TM, Edvardsen T, et al. The diagnostic accuracy of pocket-size cardiac ultrasound performed by unselected residents with minimal training. Int J Cardiovasc Imaging 2013;29:1749-57.

47 Vignon P, Frank MBJ, Lesage J, et al. Hand-held echocardiography with Doppler capability for the assessment of critically-ill patients: is it reliable? Intensive Care Med 2004;30:718-23.

48 Vourvouri EC, Schinkel AFL, Roelandt JRTC, et al. Screening for left ventricula dysfunction using a hand-carried cardiac ultrasound device. Eur J Heart Fail 2003;5:767-74.

49 Wejner-Mik P, Kasprzak JD, Filipiak-Strzecka D, et al. Personal mobile device-based pocket echocardiograph-The diagnostic value and clinical utility. Adv Med Sci 2019:64:157-61.

50 Xie T, Chamoun AJ, McCulloch M, et al. Rapid screening of cardiac patients with a miniaturized hand-held ultrasound imager--comparisons with physical examination and conventional two-dimensional echocardiography. Clin Cardiol 2004;27:241-5. doi:10.1002/clc.4960270414 